\title{
(2) OPEN ACCESS \\ Mental health and health behaviours before and during the initial phase of the COVID-19 lockdown: longitudinal analyses of the UK Household Longitudinal Study
}

\author{
Claire L Niedzwiedz (ㄷ, ${ }^{1}$ Michael James Green (10, ${ }^{2}$ Michaela Benzeval, ${ }^{3}$ \\ Desmond Campbell, ${ }^{2}$ Peter Craig, ${ }^{2}$ Evangelia Demou, ${ }^{2}$ Alastair Leyland, ${ }^{2}$ Anna Pearce, ${ }^{2}$ \\ Rachel Thomson, ${ }^{2}$ Elise Whitley, ${ }^{2}$ Srinivasa Vittal Katikireddi ${ }^{2,4}$
}

\begin{abstract}
- Supplemental material is published online only. To view please visit the journal online (http://dx.doi.org/10.1136/ jech-2020-215060)

${ }^{1}$ Institute of Health and Wellbeing, University of Glasgow, Glasgow, UK ${ }^{2}$ MRC/CSO Social and Public Health Sciences Unit, University of Glasgow, Glasgow, UK ${ }^{3}$ Institute of Social and Economic Research, University of Essex, Colchester, UK ${ }^{4}$ Public Health Scotland, UK
\end{abstract}

Correspondence to Srinivasa Vittal Katikireddi, MRC/CSO Social \& Public Health Sciences Unit, University of Glasgow, Berkeley Square, 99 Berkeley Street, Glasgow G3 7HR, UK; vittal.katikireddi@glasgow.ac.uk

$\mathrm{CN}$ and $\mathrm{MG}$ contributed equally

Received 4 July 2020 Revised 8 September 2020 Accepted 14 September 2020 Published Online First 24 September 2020

\section{ABSTRACT}

Background There are concerns that COVID-19 mitigation measures, including the 'lockdown', may have unintended health consequences. We examined trends in mental health and health behaviours in the UK before and during the initial phase of the COVID-19 lockdown and differences across population subgroups.

Methods Repeated cross-sectional and longitudinal analysis of the UK Household Longitudinal Study, including representative samples of over 27,000 adults (aged 18+) interviewed in four survey waves between 2015 and 2020. A total of 9748 adults had complete data for longitudinal analyses. Outcomes included psychological distress (General Health Questionnaire-12), loneliness, current cigarette smoking, use of e-cigarettes and alcohol consumption. Cross-sectional prevalence estimates were calculated and multilevel Poisson regression assessed associations between time period and the outcomes of interest, as well as differential associations by age, gender, education level and ethnicity. Results Psychological distress increased 1 month into lockdown with the prevalence rising from $19.4 \%(95 \% \mathrm{Cl}$ $18.7 \%$ to $20.1 \%)$ in $2017-2019$ to $30.6 \%(95 \% \mathrm{Cl}$ $29.1 \%$ to $32.3 \%$ ) in April 2020 ( $R R=1.3,95 \% \mathrm{Cl} 1.2$ to 1.4). Groups most adversely affected included women, young adults, people from an Asian background and those who were degree educated. Loneliness remained stable overall ( $R R=0.9,95 \% \mathrm{Cl} 0.6$ to 1.5). Smoking declined $(\mathrm{RR}=0.9,95 \% \mathrm{Cl}=0.8,1.0)$ and the proportion of people drinking four or more times per week increased $(\mathrm{RR}=1.4,95 \% \mathrm{Cl} 1.3$ to 1.5$)$, as did binge drinking ( $R R=1.5,95 \% \mathrm{Cl} 1.3$ to 1.7 ).

Conclusions Psychological distress increased 1 month into lockdown, particularly among women and young adults. Smoking declined, but adverse alcohol use generally increased. Effective measures are required to mitigate negative impacts on health.

\section{INTRODUCTION}

The coronavirus disease 2019 (COVID-19) pandemic has led to large-scale societal changes in many countries. Governments have introduced substantial restrictions to people's movement, including limiting the potential to attend work and school, or see friends and family. ${ }^{12}$ Such 'lockdown' measures could have large impacts on health and health inequalities. $^{3} 4$ While some impacts could arise from reduced access to healthcare during lockdown, ${ }^{5}$ lockdown measures themselves could have direct consequences on mental health and health-related behaviours.

Research prior to the pandemic has suggested quarantine is linked to several negative psychological outcomes. ${ }^{6}$ During the COVID-19 pandemic, concerns have been repeatedly raised about potentially long-lasting harms to mental health. ${ }^{7}$ Similarly, health-related behaviours such as alcohol consumption and smoking could be subject to rapid change in either direction. Increased stress during lockdown could increase consumption, ${ }^{89}$ while greater awareness of health risks, reduced availability and socialising could reduce consumption.

The UK Government introduced strict physical distancing measures, or 'lockdown' on the 23 March 2020, with other mitigation measures being introduced throughout March (online appen dix 1 Box S1). ${ }^{10}$ This restricted the general population to staying at home, unless required to leave for the purposes of carrying out an essential job (referred to as a 'keyworker', such as transport, education, food and health and social care workers), to buy necessary items or to take exercise.

Understanding the impact of lockdown is important as further periods of physical distancing are likely to be necessary in many countries for some time, especially as the possibility of further waves of infection remain. These impacts may disproportionately affect specific population subgroups, with concerns that young people, women and disadvantaged socioeconomic groups may be at greater risk. We investigated the impact of the UK's COVID-19 lockdown on mental health and health behaviours, as well as whether any observed impacts differed by age, gender, ethnicity and education level.

\section{METHODS}

\section{Data source}

The UK Household Longitudinal Study (also referred to as 'Understanding Society') is a nationally representative longitudinal household panel study, based on a clustered-stratified probability sample of UK households, described in detail previously. ${ }^{11}$ All adults (aged $16+$ years) in chosen households are invited to participate. Data 
collection for each 'wave' usually spans 24 months, with participants re-interviewed annually by online, face-to-face or telephone survey. We used pre-pandemic data from wave 7 (2015-2017), wave 8 (2016-2018) and wave 9 (2017-2019), with household response rates of $81-84 \%{ }^{11}{ }^{12}$ Following the pandemic's onset, an additional wave of data was collected via online survey between 24th and 30th April 2020 (referred to as the COVID-19 wave A- henceforth the 'CA wave'). ${ }^{13}$ The response rate for the CA wave was $48.6 \%$ of those who took part in wave $9 .{ }^{14} 15$ We analysed data from all adults aged $18+$ years who participated in each wave for repeated cross-sectional analysis (excluding proxy interviews). When analysing educational inequalities we restricted analyses to adults aged $25+$ years as educational attainment tends to be stable from that age onwards. ${ }^{16}$ For longitudinal analysis, we included participants with complete data from all four waves and aged $18+$ years during wave 9 .

The University of Essex Ethics Committee has approved all data collection for the Understanding Society main study and COVID wave. No additional ethical approval was necessary for this secondary data analysis.

\section{Outcomes}

Mental health was assessed at all four waves using the General Health Questionnaire-12 (GHQ-12), which is a screening tool for psychological distress that has been validated for use in epidemiological studies. ${ }^{17}$ Respondents scoring 4 or more (out of a possible total of 12) are likely to be experiencing anxiety and/or depression. ${ }^{18} 19$ To better understand the driving symptoms of any change in psychological distress we also considered each individual GHQ item in subsidiary analyses, investigating trends in the proportion of respondents who selected the two most adverse response categories for each question. We also conducted sensitivity analyses with the item on enjoyment of day-to-day activities removed (since this could be affected by lockdown restrictions without necessarily indicating poor mental health), and with the cut-off point reduced to 3 or more symptoms, as a way of examining increases in less severe psychological distress and to enable comparison with other studies using this definition. Loneliness was assessed at wave 9 and the CA wave by asking participants: 'in the last 4 weeks, how often did you feel lonely?' and respondents were able to answer hardly ever or never, some of the time, or often. In the statistical models, this was converted to a binary variable (often felt lonely vs all other responses).

We also assessed three health behaviour outcomes: cigarette smoking, e-cigarette use and alcohol consumption. Participants were asked 'do you smoke cigarettes? Please do not include electronic cigarettes (e-cigarettes)' and those who answered 'yes' were then asked, 'approximately how many cigarettes a day do you usually smoke, including those you roll yourself?'. We defined cigarette smoking (excluding e-cigarettes) as current smoker versus non-smoker and the number of cigarettes per day was calculated $(<10,10-19,20+$ cigarettes per day) for subsidiary analyses. Current e-cigarette use was defined on the basis of having used e-cigarettes at least once a week (waves 8, 9 and CA wave). Information about alcohol consumption was collected (waves 7,9 and CA wave) using the Alcohol Use Disorders Identification Test for Consumption (AUDIT-C) instrument. ${ }^{20}$ However, the CA wave contained some modifications including asking about drinking behaviour over the last 4 weeks, rather than the last year. We therefore looked at three key outcomes: binge drinking ( $6+$ drinks in a single sitting on a weekly basis), frequency of alcohol consumption $(4+$ times per week) and heavy drinking $(5+$ drinks on a typical day when drinking).

\section{Covariates}

We adjusted for a range of potential confounders that were likely causes of the outcomes and that did not lie on the causal pathway between lockdown and the outcomes: age group (18-24, 25-44, $45-64,65+$ years at wave 9) and self-reported gender (male/ female). Highest education level was coded as: degree-level or equivalent qualifications, A-level/AS-level or equivalent, General Certificate of Secondary Education (GCSE) or equivalent, and no qualifications. Race/ethnicity was categorised as: white, Asian, black, mixed and other, but recoded to binary (white and nonwhite) for the statistical models due to small numbers within specific ethnic minority groups. Interview year as a continuous variable accounted for temporal trends.

\section{Statistical analysis}

Prevalence estimates (with 95\% CIs) for each outcome were calculated in repeated cross-sectional analyses using all complete sets of responses from waves 7 to 9 and the CA wave. Crosssectional inverse probability weights provided with the data were used to adjust for attrition and to create estimates that were representative of the general population over time (see online appendix 1 for details of the weights). This was supplemented with additional weighting for differences in outcome nonresponse by age, gender, ethnicity and education. We repeated cross-sectional analyses stratified by gender, age group, ethnicity and education level.

We then restricted our sample to individuals with repeated measures for all relevant waves for longitudinal analysis $(n=9748)$. We conducted multi-level Poisson regression with robust SEs, to assess associations between outcomes and the time period an observation was taken in (CA wave or prior), adjusting for age, gender, race/ethnicity and interview year. Poisson regression was used to calculate relative risks. ${ }^{21}$ Robust SEs were used to improve the accuracy of estimated $95 \%$ CIs and p-values given the data are clustered. We carried out a complete case analysis, using longitudinal inverse probability weights constructed for these models to adjust for attrition and missing data (see online appen dix 1 for further details). We tested for differential associations by fitting interaction terms for age group, gender, educational level and race/ethnicity. Statistical analysis was conducted using Stata/ MP 15.1 and R version 3.6.0 for the figures.

\section{RESULTS}

Table 1 describes the individuals included in the repeated crosssectional analysis by wave, after excluding participants with missing data (see suplemental figure S1 for STROBE diagram and online supplemental table S1 for details of the longitudinal sample). The sample at the CA wave in April 2020 was: 52.0\% female, 36.8\% were degree level educated, 9.2\% were from ethnic minority groups and the mean age of participants was 49.5 (95\% CI 48.7 to 50.2) years. Weighted prevalence estimates for the key outcomes before and during the COVID-19 pandemic are shown in figure 1 and online supplemental table S2 (online appendix 2 contains prevalences for each wave and outcome by subgroup).

\section{Psychological distress}

Psychological distress has steadily increased over time from $17.6 \%$ (95\% CI 17.0 to 18.2 ) in $2015-2017$ (wave 7 ) to $19.4 \%$ 
Table 1 Description of the repeated cross-sectional samples (weighted \%)

\begin{tabular}{|c|c|c|c|c|c|c|c|c|}
\hline & \multicolumn{2}{|c|}{$\begin{array}{l}\text { Wave } 7 \\
\text { (2015-2017) }\end{array}$} & \multicolumn{2}{|c|}{$\begin{array}{l}\text { Wave } 8 \\
(2016-2018)\end{array}$} & \multicolumn{2}{|c|}{$\begin{array}{l}\text { Wave } 9 \\
(2017-2019)\end{array}$} & \multicolumn{2}{|c|}{$\begin{array}{l}\text { COVID-19 (CA) } \\
\text { Wave } \\
\text { (April 2020) }\end{array}$} \\
\hline & $\mathrm{N}$ & $\%$ & $\mathrm{~N}$ & $\%$ & $\mathrm{~N}$ & $\%$ & $\mathrm{~N}$ & $\%$ \\
\hline \multicolumn{9}{|c|}{ Age group } \\
\hline $18-24$ & 3009 & 11.1 & 2619 & 11.2 & 2292 & 11.6 & 655 & 10.8 \\
\hline $25-44$ & 8504 & 30.7 & 7584 & 30.3 & 6511 & 29.5 & 2727 & 29.4 \\
\hline $45-64$ & 9766 & 35.0 & 9202 & 35.1 & 8496 & 35.3 & 4661 & 37.1 \\
\hline $65+$ & 5862 & 23.2 & 5826 & 23.4 & 5524 & 23.6 & 2934 & 22.7 \\
\hline \multicolumn{9}{|l|}{ Gender } \\
\hline Male & 12106 & 48.0 & 11308 & 47.9 & 10216 & 47.8 & 4609 & 48.0 \\
\hline Female & 15035 & 52.1 & 13923 & 52.1 & 12607 & 52.2 & 6368 & 52.0 \\
\hline \multicolumn{9}{|c|}{ Ethnic group } \\
\hline White & 22238 & 92.0 & 20905 & 92.1 & 19214 & 92.1 & 9814 & 90.8 \\
\hline Asian & 2870 & 4.3 & 2587 & 4.3 & 2224 & 4.3 & 718 & 5.1 \\
\hline Black & 1284 & 1.9 & 1083 & 1.9 & 844 & 1.9 & 216 & 1.9 \\
\hline Mixed & 531 & 1.1 & 476 & 1.1 & 405 & 1.2 & 176 & 1.6 \\
\hline Other & 218 & 0.6 & 180 & 0.6 & 136 & 0.6 & 53 & 0.6 \\
\hline \multicolumn{9}{|c|}{ Education level } \\
\hline Degree & 10504 & 36.8 & 9903 & 37.0 & 9131 & 37.4 & 5228 & 36.8 \\
\hline A Level & 3231 & 11.4 & 2965 & 11.7 & 2699 & 12.0 & 1269 & 11.4 \\
\hline GCSE & 7246 & 28.2 & 6733 & 28.3 & 6029 & 28.2 & 2737 & 28.2 \\
\hline None & 6160 & 23.7 & 5630 & 23.0 & 4964 & 22.5 & 1743 & 23.7 \\
\hline Total & 27141 & 100.0 & 25231 & 100.0 & 22823 & 100.0 & 10977 & 100.0 \\
\hline
\end{tabular}

(95\% CI 18.7 to 20.1 ) in 2017-2019 (wave 9), but substantially increased to $30.6 \%$ (95\% CI 29.1 to 32.3 ) during the COVID-19 pandemic in April 2020 (figure 1 and online supplemental table S2). All symptoms of psychological distress worsened over this period (figure 2). The symptom which had the largest deterioration was enjoyment of normal day-to-day activities. Worsening symptoms were also observed for concentration, sleep, feelings of unhappiness and loss of purpose. In contrast, there was less of an apparent increase in feelings of worthlessness, an inability to overcome difficulties and lacking confidence. In sensitivity analyses using $3+$ symptoms as the cut-off point, the prevalence of psychological distress increased from 23.7\% (95\% CI 23.0 to 24.5 ) in 2017-2019 (wave 9) to $38.0 \%$ (95\% CI 36.3 to 39.7 ) in the CA wave (online supplemental table S2). We also investigated whether the decline in enjoyment of day-to-day activities was driving the increase in psychological distress. Removing this item reduced the magnitude of the increase, but it remained substantial (online supplemental table S2).

The increase in psychological distress was most pronounced among people aged under 45 years, as well as among the most educated groups (figure 3 and online appendix 2). Women were also more adversely affected than men; among women, the prevalence of psychological distress increased from $23.0 \%$ (95\% CI 22.0 to 23.9 ) in $2017-2019$ to $36.8 \%$ (95\% CI 34.8 to 38.8 ) during the pandemic period. Asian minority ethnic groups also experienced a large increase in psychological distress; from $18.7 \%$ (95\% CI 16.4 to 21.2 ) to $34.9 \%$ (95\% CI 27.3 to 43.2 ) (online appendix 2).

Longitudinal regression models (table 2) adjusted for age, gender, race/ethnicity and interview year demonstrated that the risk of psychological distress was elevated during the pandemic compared with the pre-pandemic period (RR: $1.3,95 \%$ CI 1.2 to 1.4), taking into account prior trends. In sensitivity analyses using the lower cut-off threshold for GHQ, the RR was 1.4 (95\% CI 1.3 to 1.5$)$. There was evidence of differential effects by age group, gender and education level when examining statistical interactions with time period (online supplemental table S3).

\section{Loneliness}

Overall, loneliness remained relatively stable before and during the lockdown period (figure 1). However, in repeated cross-sectional analysis, there were differences by age group (figure 3), with younger people experiencing higher overall levels of loneliness, as well as a large increase in loneliness (from $13.3 \%$ (95\% CI 11.6 to 15.3 ) to $20.2 \%$ (95\% CI 16.0 to 25.2)) during lockdown. Loneliness also slightly increased among women, but fell among men. In longitudinal analyses, differences by age were less apparent (although this analysis had less statistical power), but there was evidence for an interaction between gender and time period (online supple mental table S4).

\section{Alcohol consumption}

Binge drinking increased from 10.8\% (95\% CI 10.3 to 11.3 ) in wave 9 (2017-2019) to $16.2 \%$ (95\% CI 15.0 to 17.4 ) during lockdown (figure 1), as did the proportion of people reporting drinking four or more times a week (13.7\% (95\% CI 13.1 to 14.3 ) to $22.0 \%$ (95\% CI 20.6 to 23.4$)$ ). Differences by age group and gender were apparent. Binge drinking remained stable in the youngest age group but increased in those aged 25 and over (figure 3). Binge drinking and frequent drinking also increased more among women, white ethnic groups and those with degree-level education.

The proportion of people reporting drinking five or more drinks during a typical day when drinking decreased from 13.6\% (95\% CI 13.0 to 14.3 ) during wave 9 (2017-2019) to 5.6\% (95\% CI 4.8 to 6.4 ) during the pandemic lockdown (figure 1). This decrease was marked in the youngest age group, falling from 31.9\% (95\% CI 29.5 to 34.5 ) during wave 9 to $8.5 \%$ (95\% CI 5.4 to 13.2 ) during lockdown (figure 3).

Results from longitudinal models supported cross-sectional analyses (table 2), with the risk of binge drinking (RR 1.5, 95\% CI 1.3 to 1.7 ) and frequent drinking (RR 1.4 , 95\% CI 1.3 to 1.5 ) increasing during the pandemic, while risk of having $5+$ drinks on a typical drinking day was reduced (RR 0.4 , 95\% CI 0.3 to 0.5 ). There were also statistical interactions between time period and age group, as well as time period and gender for all alcohol outcomes and with education level for binge drinking (online supplemental table S5-7).

\section{Cigarette smoking and e-cigarette use}

Current cigarette smoking decreased during lockdown (figure 1 and online supplemental table S2). The decrease in smoking was more apparent in younger age groups and among men (figure 3) and seems driven by a decline in lighter smokers (online supplemental table S2). Longitudinal models demonstrated that risk of smoking reduced during the pandemic (RR 0.9, 95\% CI 0.8 to 1.0) (table 2), but there were no statistically significant $(\mathrm{p}<0.05)$ interactions with age group, gender, race/ethnicity or education level (online supple mental table S8). In the longitudinal analyses, risk of e-cigarette use was also lower during the pandemic (RR $0.7,95 \%$ CI 0.5 to 0.9 ) (table 2), but no statistically significant interactions were found with the subgroups examined (online supplemental table S9). 


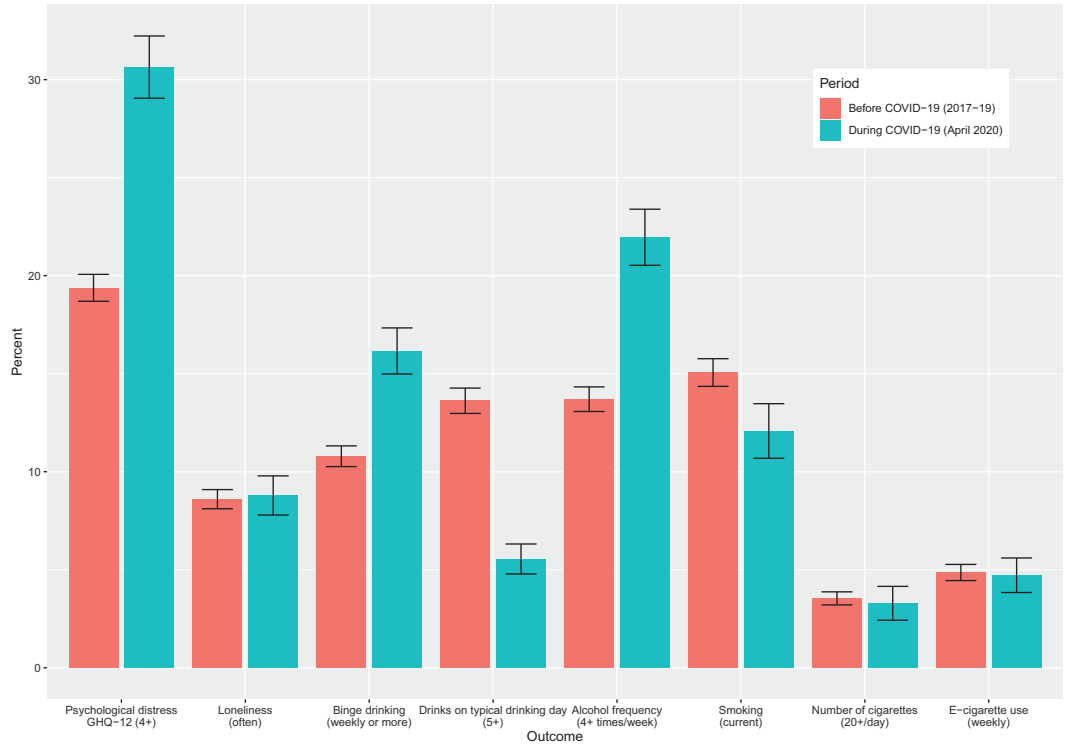

Figure 1 Mental health and health behaviours before (2017-2019) and during the COVID-19 lockdown (April 2020).

\section{DISCUSSION}

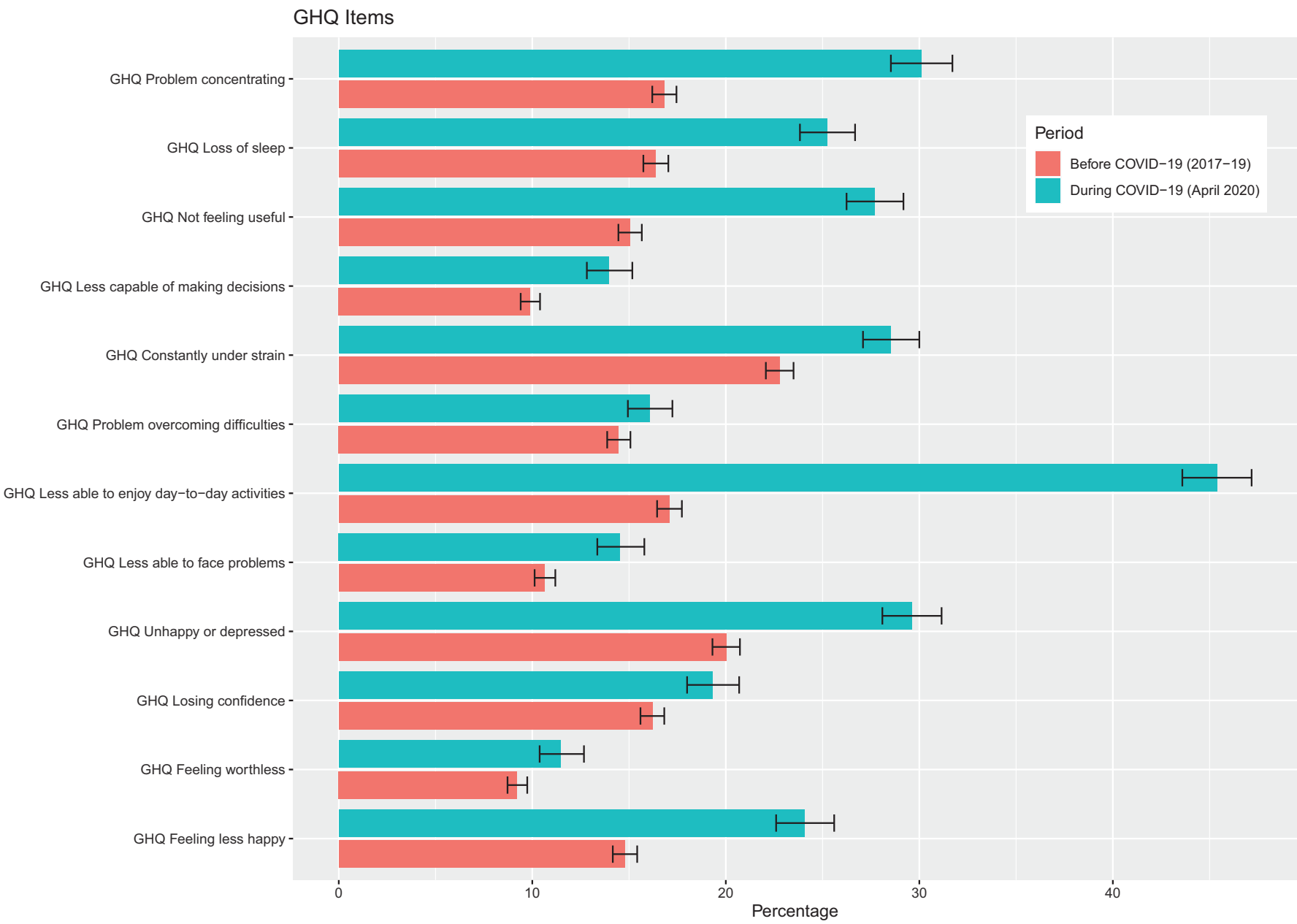

Figure 2 Psychological distress (General Health Questionnaire items) before (2017-2019) and during the COVID-19 lockdown (April 2020).

Psychological distress substantially increased in the UK following the COVID-19 pandemic. Groups most adversely affected included women and younger people. The increase in psychological distress, measured after the first month of lockdown, appeared to be driven by a reduction in enjoyment of normal day-to-day activities, as well as increased difficulties 

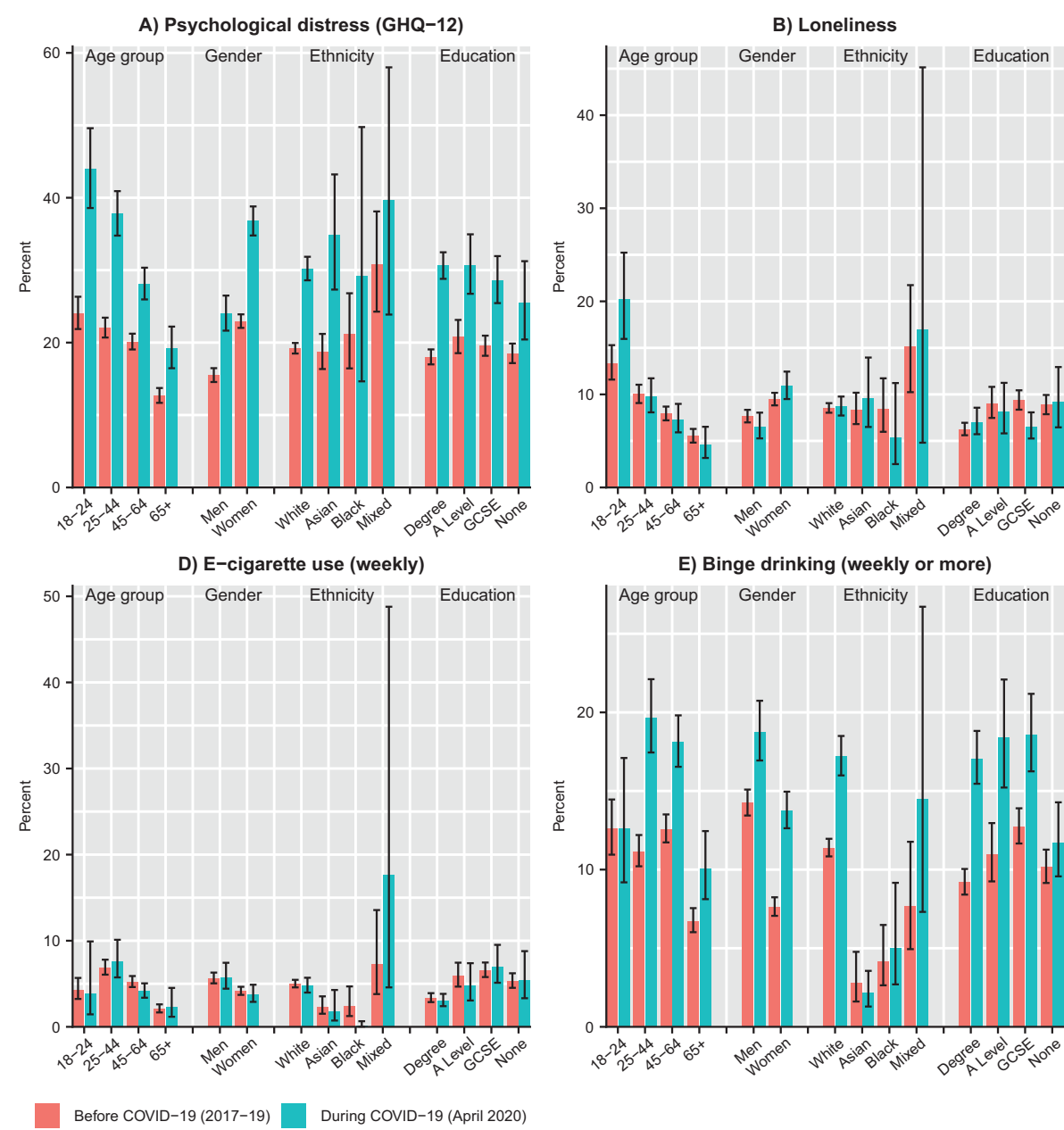

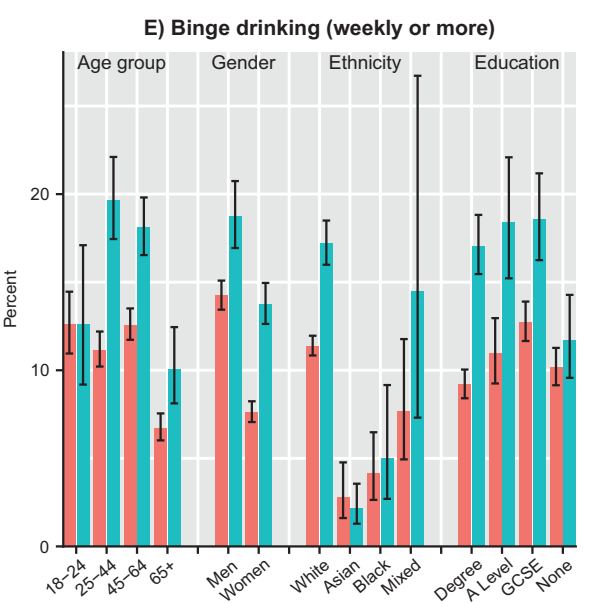

Figure 3 Mental health and health behaviours before (2017-2019) and during the COVID-19 lockdown (April 2020) by subgroup.

with concentration and sleep, and feelings of unhappiness. Overall, loneliness remained relatively stable. Cigarette smoking declined, and this reduction appears to reflect cessation among lighter smokers. The frequency of drinking four or more times a week and binge drinking increased, particularly among those aged over 25 and white ethnic groups.

Our study has several strengths. We used a large nationally representative longitudinal dataset. We also checked the variation in our outcomes before the pandemic and found that secular trends tended to be small compared to changes observed during the pandemic. Some limitations should be noted. First, survey non-participation may have introduced bias in our estimates, especially as the response rate in the COVID survey was lower than usual. However, weights were used to reduce concerns about non-response and attrition. Second, there were changes in the modality by which the COVID survey was administered (moving from mixed mode (face-to-face, web and phone) to online surveys), which may have led to modest reporting changes. However, empirical investigation suggested this is unlikely to have biased responses. ${ }^{22}$ Relatedly, there were minor changes to the questionnaire items about alcohol consumption, so that questions related to the pandemic period rather than the entire previous year. This meant that a modified version of the AUDIT-C scale was used, which is not strictly comparable with previous years and so these initial results should be interpreted with caution. Alcohol consumption is also known to be underreported in surveys. ${ }^{23} 24$ The pandemic context may have also influenced participant reporting more broadly. For example, the increase in being less able to enjoy usual activities may not reflect anhedonia, but rather the reality of experiencing lockdown and could be considered a normal response. Relatedly, what people perceive as a 'typical' drinking day is likely to have changed, especially among younger people, which could explain the conflicting results for this measure of alcohol consumption.

While a body of literature is developing to articulate the expected indirect impacts of the pandemic, ${ }^{3} 725$ empirical research on how mental health and health-related behaviours have changed remains limited and largely based on nonrepresentative samples. ${ }^{26}$ A repeated cross-sectional analysis comparing results of two different representative surveys conducted before and during the pandemic in the USA found a marked increase in psychological distress among adults, from $3.9 \%$ to $13.6 \% .{ }^{27}$ Furthermore, younger people experienced the greatest relative increase in poor mental health, echoing our findings. While longitudinal evidence on changes in consumption of tobacco and alcohol are limited, cross-sectional surveys have been conducted which asked about self-perceived changes in behaviour. A representative survey conducted on behalf of the charity Alcohol Change UK found that 21\% of adults who normally drink alcohol self-reported increased consumption, but $35 \%$ reduced how often they drink or have stopped drinking altogether. $^{28}$ Similarly, an online non-representative survey with data collection following the pandemic also found that 
Table 2 Risk ratios (RR) derived from the multilevel Poisson models for mental health and health behaviour outcomes

\begin{tabular}{|c|c|c|c|c|c|c|c|c|}
\hline & $\begin{array}{l}\text { Psychological distress } \\
\text { (GHQ-12, 4+ cut-off) }\end{array}$ & $\begin{array}{l}\text { Psychological distress } \\
\text { (GHQ-12, 3+ cut-off) }\end{array}$ & Loneliness & $\begin{array}{l}\text { Binge drinking } \\
\text { (weekly or more) }\end{array}$ & $\begin{array}{l}\text { Alcohol frequency } \\
(4+\text { times per } \\
\text { week) }\end{array}$ & $\begin{array}{l}5+\text { drinks on } \\
\text { typical } \\
\text { drinking day }\end{array}$ & $\begin{array}{l}\text { Current } \\
\text { cigarette } \\
\text { smoking } \\
\end{array}$ & $\begin{array}{l}\text { Regular } \\
\text { e-cigarettes }\end{array}$ \\
\hline & $\begin{array}{l}\text { RR } \\
{[95 \% \mathrm{Cl}]} \\
\end{array}$ & $\begin{array}{l}\text { RR } \\
{[95 \% \mathrm{Cl}]} \\
\end{array}$ & $\begin{array}{l}\text { RR } \\
{[95 \% \mathrm{Cl}]} \\
\end{array}$ & $\begin{array}{l}\text { RR } \\
{[95 \% \mathrm{Cl}]} \\
\end{array}$ & $\begin{array}{l}\text { RR } \\
{[95 \% \mathrm{Cl}]}\end{array}$ & $\begin{array}{l}\text { RR } \\
{[95 \% \mathrm{Cl}]} \\
\end{array}$ & $\begin{array}{l}\text { RR } \\
{[95 \% \mathrm{Cl}]} \\
\end{array}$ & $\begin{array}{l}\text { RR } \\
{[95 \% \mathrm{Cl}]} \\
\end{array}$ \\
\hline Interview year & $1.06^{* * *}[1.03,1.09]$ & $\begin{array}{l}1.05^{* * *} \\
{[1.02,1.07]}\end{array}$ & $\begin{array}{l}1.00 \\
{[0.83,1.20]}\end{array}$ & $\begin{array}{l}1.02 \\
{[0.98,1.06]}\end{array}$ & $\begin{array}{l}1.05^{* * *} \\
{[1.03,1.08]}\end{array}$ & $\begin{array}{l}1.02 \\
{[0.98,1.06]}\end{array}$ & $\begin{array}{l}0.99 \\
{[0.97,1.01]}\end{array}$ & $\begin{array}{l}1.11^{*} \\
{[1.00,1.22]}\end{array}$ \\
\hline Age group: $18-24$ & $\begin{array}{l}2.33^{* * *} \\
{[2.03,2.67]}\end{array}$ & $\begin{array}{l}2.08^{* * *} \\
{[1.85,2.34]}\end{array}$ & $\begin{array}{l}4.76^{* * *} \\
{[3.55,6.39]}\end{array}$ & $\begin{array}{l}1.59^{* * *} \\
{[1.25,2.01]}\end{array}$ & $\begin{array}{l}0.17^{* * *} \\
{[0.13,0.23]}\end{array}$ & $\begin{array}{l}15.29^{* * *} \\
{[11.73,19.93]}\end{array}$ & $\begin{array}{l}2.85^{* * *} \\
{[1.62,5.02]}\end{array}$ & $\begin{array}{l}2.04 \\
{[0.95,4.39]}\end{array}$ \\
\hline $25-44$ & $\begin{array}{l}2.01^{* * *} \\
{[1.83,2.22]}\end{array}$ & $\begin{array}{l}1.82^{* * *} \\
{[1.68,1.98]}\end{array}$ & $\begin{array}{l}2.73^{* * *} \\
{[2.15,3.46]}\end{array}$ & $\begin{array}{l}1.73^{* * *} \\
{[1.50,2.01]}\end{array}$ & $\begin{array}{l}0.48^{* * *} \\
{[0.43,0.54]}\end{array}$ & $\begin{array}{l}7.62^{* * *} \\
{[6.06,9.59]}\end{array}$ & $\begin{array}{l}6.56^{* * *} \\
{[4.42,9.75]}\end{array}$ & $\begin{array}{l}6.23^{* * *} \\
{[4.14,9.37]}\end{array}$ \\
\hline $45-64$ & $\begin{array}{l}1.71 * * * \\
{[1.55,1.88]}\end{array}$ & $\begin{array}{l}1.54^{* * *} \\
{[1.43,1.67]}\end{array}$ & $\begin{array}{l}2.02 * * * \\
{[1.61,2.54]}\end{array}$ & $\begin{array}{l}1.98^{* * *} \\
{[1.74,2.26]}\end{array}$ & $\begin{array}{l}0.87^{* *} \\
{[0.79,0.95]}\end{array}$ & $\begin{array}{l}4.46^{* * *} \\
{[3.55,5.62]}\end{array}$ & $\begin{array}{l}5.29 * * * \\
{[3.56,7.87]}\end{array}$ & $\begin{array}{l}3.94^{* * *} \\
{[2.70,5.74]}\end{array}$ \\
\hline \multicolumn{9}{|l|}{$65+(\mathrm{ref})$} \\
\hline \multicolumn{9}{|l|}{ Gender: Men (ref) } \\
\hline Women & $\begin{array}{l}1.58^{* * *} \\
{[1.48,1.69]}\end{array}$ & $\begin{array}{l}1.51 * * * \\
{[1.43,1.60]}\end{array}$ & $\begin{array}{l}1.64^{* * *} \\
{[1.41,1.91]}\end{array}$ & $\begin{array}{l}0.53^{* * *} \\
{[0.49,0.59]}\end{array}$ & $\begin{array}{l}0.62^{* * *} \\
{[0.57,0.67]}\end{array}$ & $\begin{array}{l}0.52^{* * *} \\
{[0.46,0.59]}\end{array}$ & $\begin{array}{l}1.00 \\
{[0.82,1.22]}\end{array}$ & $\begin{array}{l}0.76^{*} \\
{[0.58,0.99]}\end{array}$ \\
\hline \multicolumn{9}{|c|}{ Race/ethnicity: White (ref) } \\
\hline Non-white & $\begin{array}{l}1.14^{*} \\
{[1.02,1.27]}\end{array}$ & $\begin{array}{l}1.08 \\
{[0.98,1.19]}\end{array}$ & $\begin{array}{l}1.12 \\
{[0.88,1.44]}\end{array}$ & $\begin{array}{l}0.27^{* * *} \\
{[0.20,0.36]}\end{array}$ & $\begin{array}{l}0.34^{* * *} \\
{[0.26,0.43]}\end{array}$ & $\begin{array}{l}0.30^{* * *} \\
{[0.22,0.40]}\end{array}$ & $\begin{array}{l}1.19 \\
{[0.88,1.61]}\end{array}$ & $\begin{array}{l}0.52^{*} \\
{[0.32,0.86]}\end{array}$ \\
\hline \multicolumn{9}{|l|}{ Period: Pre-COVID-19 } \\
\hline During COVID-19 & $\begin{array}{l}1.28^{* * *} \\
{[1.15,1.42]}\end{array}$ & $\begin{array}{l}1.38^{* * *} \\
{[1.25,1.51]}\end{array}$ & $\begin{array}{l}0.90 \\
{[0.55,1.47]}\end{array}$ & $\begin{array}{l}1.48^{* * *} \\
{[1.27,1.73]}\end{array}$ & $\begin{array}{l}1.38^{* * *} \\
{[1.26,1.51]}\end{array}$ & $\begin{array}{l}0.40^{* * *} \\
{[0.33,0.47]}\end{array}$ & $\begin{array}{l}0.89^{* *} \\
{[0.82,0.97]}\end{array}$ & $\begin{array}{l}0.66^{*} \\
{[0.48,0.91]}\end{array}$ \\
\hline Observations & 38992 & 38992 & 19496 & 29244 & 29244 & 29244 & 38992 & 29244 \\
\hline
\end{tabular}

${ }^{*} \mathrm{p}<0.05,{ }^{* *} \mathrm{p}<0.01,{ }^{* * *} \mathrm{p}<0.001$.

$95 \%$ Cls in brackets.

self-reported tobacco and e-cigarette use reduced by about onequarter. $^{29}$

Our study has important implications for public health policy. The substantial increase in psychological distress in the UK highlights the potential tension between implementing lockdown measures to control the pandemic and the risk of health harms that such action could have. By comparison, in England poor mental health after the Great Recession (assessed using the same GHQ outcome used in this study) increased from $13.7 \%$ to $16.4 \%{ }^{30}$-an effect size approximately one-quarter of that observed in this study. Finding that women have been disproportionately affected illustrates broader unequal power relations within society, with women more likely to experience the additional burden of childcare and more likely to work in sectors worst affected by the pandemic. ${ }^{31}$ It is worth noting that this more recent decline in mental health among women occurs after a period of austerity, during which women's mental health had already been showing adverse trends. ${ }^{32-34}$ The reduction in smoking, despite the adverse societal circumstances, may illustrate the importance of the availability of these products in influencing behaviour. There is an increasing evidence base which suggests that availability of unhealthy commodities drives consumption and contributes to health inequalities. ${ }^{35}$ The trends in alcohol consumption merit further exploration. The frequency of alcohol consumption and binge drinking appears to have increased, but the proportion of people drinking $5+$ drinks on a typical day when drinking decreased. This may reflect the change in what a typical drinking day is (eg, going to the pub with friends compared with drinking at home) and the change in the frequency of alcohol consumption.

Further research is needed to understand mechanisms by which these impacts may be arising and whether the large increase in psychological distress remains following changes to the lockdown. As we did not investigate differences by country of the UK, future research should investigate whether there are differential trends over the longer-term course of the pandemic by country as the mitigation policies began to diverge. We also found psychological distress increased among the most educated groups, which may reflect that this group was more likely to move to remote working during the pandemic, and for some, this was combined with the home-schooling of children. Monitoring socioeconomic groups to see if they are able to recover from the initial shock of the lockdown will be important to understand the implications for mental health inequalities. While the UK Government introduced aggressive fiscal policies to minimise adverse economic risks, it is likely that at least some of these impacts reflect the start of a potentially long-lasting economic crisis. ${ }^{36}$ Understanding to what extent health is also being impacted by income and unemployment shocks will help inform decisions about ongoing support over the coming months and years. ${ }^{37}$ However, improved psychological support, including access to mental health services, may also be necessary. Our research provides an early picture of the broader consequences of the pandemic_clearly, longer-term monitoring will be necessary. Poor mental health is an important predictor of future mortality and several physical health conditions. ${ }^{38}{ }^{39}$ Given this, further monitoring of the determinants of health, as well as health outcomes, are required.

\section{What is already known on this topic}

- Countries around the world have implemented radical COVID-19 lockdown measures, with concerns that these may have unintended consequences for a broad range of health outcomes.

- Evidence on the impact of lockdown measures on mental health and health-related behaviours remains limited. 


\section{What this study adds}

In the UK, psychological distress markedly increased during lockdown, with women particularly adversely affected.

- Cigarette smoking fell, but adverse drinking behaviour generally increased.

\section{Twitter Srinivasa Katikireddi @vkatikireddi.}

Acknowledgements We would like to thank the participants of the Understanding Society study. The Understanding Society COVID-19 study is funded by the Economic and Social Research Council (ES/K005146/1) and the Health Foundation (2076161). Fieldwork for the survey is carried out by Ipsos MORI and Kantar. Understanding Society is an initiative funded by the Economic and Social Research Council and various government departments, with scientific leadership by the Institute for Social and Economic Research, University of Essex.

Contributors SVK and CLN conceived the idea for the study. CLN, MJG and SVK conducted the analysis, drafted the manuscript and had full access to the study datasets and act as guarantors. CLN, MJG, MB, DDC, PC, ED, AHL, AP, RMT, EW and SVK contributed to the study design, interpretation of the findings and critically revised the manuscript. All authors approved the final version of the paper.

Funding MJG, DC, PC, ED, AL, AP, EW and SVK acknowledge funding from the Medical Research Council (MC_UU_12017/13) and Scottish Government Chief Scientist Office (SPHSU13). In addition, CLN acknowledges funding from a Medical Research Council Fellowship (MR/R024774/1); AP acknowledges funding from the Wellcome Trust (205412/Z/16/Z); RT acknowledges funding from a Wellcome Trust Research Fellowship for Health Professionals (218105/Z/19/Z); and SVK acknowledges funding from an NRS Senior Clinical Fellowship (SCAF/15/02). MB acknowledges funding from the Economic and Social Research Council (ES/N00812X/ 1). The funders had no role in the study design, data collection, data analysis, data interpretation, or writing of the report.

Competing interests None declared.

Patient consent for publication Not required.

Provenance and peer review Not commissioned; externally peer reviewed.

Data availability statement Understanding Society deidentified survey participant data are available through the UK Data Service (URLs: http://doi.org/10.5255/UKDASN-6614-13; http://doi.org/10.5255/UKDA-SN-8644-3). Researchers who would like to use Understanding Society need to register with the UK Data Service (URL: https:// ukdataservice.ac.uk/) before being allowed to download datasets.

Supplemental material This content has been supplied by the author(s). It has not been vetted by BMJ Publishing Group Limited (BMJ) and may not have been peerreviewed. Any opinions or recommendations discussed are solely those of the author(s) and are not endorsed by BMJ. BMJ disclaims all liability and responsibility arising from any reliance placed on the content. Where the content includes any translated material, BMJ does not warrant the accuracy and reliability of the translations (including but not limited to local regulations, clinical guidelines, terminology, drug names and drug dosages), and is not responsible for any error and/ or omissions arising from translation and adaptation or otherwise.

Open access This is an open access article distributed in accordance with the Creative Commons Attribution 4.0 Unported (CC BY 4.0) license, which permits others to copy, redistribute, remix, transform and build upon this work for any purpose, provided the original work is properly cited, a link to the licence is given, and indication of whether changes were made. See: https://creativecommons.org/licenses/ by $/ 4.0 /$.

\section{ORCID iDs}

Claire L Niedzwiedz http://orcid.org/0000-0001-6133-4168

Michael James Green http://orcid.org/0000-0003-3193-2452

\section{REFERENCES}

1 Hale T, Webster S, Petherick A, et al. Oxford COVID-19 government response tracker. Oxford: Blavatnik School of Government, 2020.

2 International Monetary Fund. Policy responses to COVID-19. Available https://www.imf. org/en/Topics/imf-and-covid19/Policy-Responses-to-COVID-19 (accessed 7 Jun 2020)

3 Douglas M, Katikireddi SV, Taulbut M, et al. Mitigating the wider health effects of COVID-19 pandemic response. BMJ 2020;369:m1557.

4 Wright L, Steptoe A, Fancourt D. Are we all in this together? Longitudinal assessment of cumulative adversities by socioeconomic position in the first 3 weeks of lockdown in the UK. J Epidemiol Community Health 2020.
5 Kuderer NM, Choueiri TK, Shah DP, et al. Clinical impact of COVID-19 on patients with cancer (CCC19): a cohort study. Lancet 2020.

6 Brooks SK, Webster RK, Smith LE, et al. The psychological impact of quarantine and how to reduce it: rapid review of the evidence. Lancet 2020;395:912-20.

7 Gunnell D, Appleby L, Arensman E, et al. Suicide risk and prevention during the COVID-19 pandemic. Lancet Psychiatry 2020;7:468-71.

8 Patwardhan P. COVID-19: risk of increase in smoking rates among England's 6 million smokers and relapse among England's 11 million ex-smokers. BJGP Open 2020; bjgpopen20X101067.

9 Clay JM, Parker MO. Alcohol use and misuse during the COVID-19 pandemic: a potential public health crisis? Lancet Public Health 2020;5:e259.

10 Dunn P, Allen L, Cameron G, et al. COVID-19 policy tracker: a timeline of national policy and health system responses to COVID-19 in England. London: Health Foundation, 2020.

11 University of Essex, Institute for Social and Economic Research. Understanding Society: The UK Household Longitudinal Study Waves 1-9 User Guide. 2019.

12 University of Essex, Institute for Social and Economic Research, NatCen Social Research, Kantar Public. Understanding Society: waves 1-9, 2009-2018 and harmonised BHPS: waves 1-18, 1991-2009. [data collection]. 12th edn. UK Data Service, SN: 6614, 2020

13 University of Essex, Institute for Social and Economic Research. Understanding Society: COVID-19 study, 2020. [data collection]. 3rd edn. UK Data Service, SN: 8644, 2020.

14 University of Essex, Institute for Social and Economic Research. Understanding Society COVID-19 User Guide. 2020.

15 Benzeval M, Burton J, Crossley TF, et al. The idiosyncratic impact of an aggregate shock: the distributional consequences of COVID-19. Available at SSRN 3615691, 2020.

16 Galobardes B, Shaw M, Lawlor DA, et al. Indicators of socioeconomic position (part 1). J Epidemiol Community Health 2006;60:7-12.

17 Goldberg DP, Gater R, Sartorius N, et al. The validity of two versions of the GHQ in the WHO study of mental illness in general health care. Psychol Med 1997;27:191-7.

18 Aalto A-M, Elovainio M, Kivimäki M, et al. The Beck Depression Inventory and General Health Questionnaire as measures of depression in the general population: a validation study using the Composite International Diagnostic Interview as the gold standard. Psychiatry Res 2012;197:163-71.

19 Holi MM, Marttunen M, Aalberg V. Comparison of the GHQ-36, the GHQ-12 and the SCL-90 as psychiatric screening instruments in the Finnish population. Nord J Psychiatry 2003;57:233-8.

20 Bradley KA, DeBenedetti AF, Volk RJ, et al. AUDIT-C as a brief screen for alcohol misuse in primary care. Alcohol Clin Exp Res 2007;31:1208-17.

21 Zou G. A modified Poisson regression approach to prospective studies with binary data. Am J Epidemiol 2004;159:702-6.

22 Davillas A, Jones AM. The COVID-19 pandemic and its impact on inequality of opportunity in psychological distress in the UK. Available at SSRN 36149402020.

23 Gorman E, Leyland AH, McCartney G, et al. Assessing the representativeness of population-sampled health surveys through linkage to administrative data on alcohol-related outcomes. Am J Epidemiol 2014;180:941-8.

24 Boniface S, Shelton N. How is alcohol consumption affected if we account for underreporting? A hypothetical scenario. Eur J Public Health 2013;23:1076-81.

25 Holmes EA, O'Connor RC, Perry VH, et al. Multidisciplinary research priorities for the COVID-19 pandemic: a call for action for mental health science. Lancet Psychiatry 2020;7:547-60.

26 Zhang J, Lu H, Zeng H, et al. The differential psychological distress of populations affected by the COVID-19 pandemic. Brain Behav Immun 2020.

27 McGinty EE, Presskreischer R, Han $\mathrm{H}$, et al. Psychological distress and loneliness reported by US adults in 2018 and April 2020. JAMA 2020;

28 Holmes S. Drinking during lockdown: headline findings. London: Alcohol Change UK 2020.

29 Klemperer EM, West JC, Peasley-Miklus C, et al. Change in tobacco and electronic cigarette use and motivation to quit in response to COVID-19. Nicotine Tob Res 2020; ntaa072.

30 Katikireddi SV, Niedzwiedz CL, Popham F. Trends in population mental health before and after the 2008 recession: a repeat cross-sectional analysis of the 1991-2010 Health Surveys of England. BMJ Open 2012;2:e001790.

31 Devine BF, Foley N. Women and the economy. London: House of Commons Library, 2020.

32 Thomson RM, Niedzwiedz CL, Katikireddi SV. Trends in gender and socioeconomic inequalities in mental health following the great recession and subsequent austerity policies: a repeat cross-sectional analysis of the Health Surveys for England. BMJ Open 2018;8:e22924.

33 Thomson RM, Katikireddi SV. Mental health and the jilted generation: using age-periodcohort analysis to assess differential trends in young people's mental health following the Great Recession and austerity in England. Soc Sci Med 2018;214:133-43.

34 Barr B, Kinderman P, Whitehead M. Trends in mental health inequalities in England during a period of recession, austerity and welfare reform 2004 to 2013. Soc Sci Med 2015;147:324-31. 
35 Macdonald L, Olsen JR, Shortt NK, et al. Do 'environmental bads' such as alcohol, fast food, tobacco, and gambling outlets cluster and co-locate in more deprived areas in Glasgow City, Scotland? Health Place 2018;51:224-31.

36 OECD. OECD economic outlook. Paris: OECD iLibrary, 2020.

37 McKee M, Stuckler D. If the world fails to protect the economy, COVID-19 will damage health not just now but also in the future. Nat Med 2020.
38 Russ TC, Stamatakis E, Hamer M, et al. Association between psychological distress and mortality: individual participant pooled analysis of 10 prospective cohort studies. BM 2012;345:e4933.

39 Batty GD, Russ TC, Stamatakis E, et al. Psychological distress in relation to site specific cancer mortality: pooling of unpublished data from 16 prospective cohort studies. BMJ 2017;356:j108. 